\title{
Analysis of Rock Burst Induced by Overlying Magmatic Rock
}

\author{
Zhenxing Chang ${ }^{1, a}$, Yue $\mathrm{Yu}^{1, b}$ \\ ${ }^{1}$ Faculty of Resource and Safety Engineering, China University of Mining and Technology (Beijing), \\ Beijing 100083, China \\ aczxing2008@163.com, byuyue.cumtb@foxmail.com
}

\begin{abstract}
Keywords: magmatic rock, fracture mechanism, numerical simulation, rock burst.
Abstract. To explore how to prevent and control rock burst of mining under the overlying magmatic rock, the 1061 working face in 106 mining area in some mine is taken as engineering background. The mining area is overlaid by three thick hard layers of magmatic rock, which lead to rock burst phenomenon. After the mining of the working face, strong pressure appeared in the stope. To guarantee safety production, this paper calculated the limit collapse distance and fracture span of magmatic rock, determined the fracture mechanism of the overlying magmatic rock, and used numerical simulation to verify the theoretical results, then propose reasonable feasible suggestions and methods for the mining of the working face, and provided significant guidance to govern rock burst of the mining area.
\end{abstract}

\section{Engineering Situation}

Basic Situation of the Mine. The total thickness of the coal-bearing strata is about $900 \mathrm{~m}$, the total thickness of coal seams is $12.60 \mathrm{~m}$, the average thickness of minable coal seams is $10.16 \mathrm{~m}$, the coal-bearing coefficient is about $1.4 \% .3_{2}, 8_{2}$ and 10 coal are relatively stable coal seams, which are the main minable coal seams. 10 coal is the current mining coal seam in the mining field. The thickness of 10 coal is $0 \sim 7.97 \mathrm{~m}, 3.05 \mathrm{~m}$ on average. The native structure of the coal seam is simple, and basically does not contain dirt band.

A wide scope of magmatic rock intrudes into the mining field, more for bedding intrusion, and the minable seam is affected by the invasion in different degrees. The magmatic rock above the 104 and 106 mining area intrudes along the $5_{2}$ coal seam, so the coal seam stability becomes worse. The primary deposit of $7_{2}$ coal seam develops better, and the intrusive magmatic rock destroys the stability and continuity of the coal seam, so it is locally minable unstable coal seam. The magmatic rock above 104 and 106 mining area bedding intruded along the roof of $7_{2}$ coal seam, and the area above 104 and 106 mining area is almost covered by bedding intrusive magmatic rock.

Basic Situation of the Working Face. The 1061 working face is the first mining face of 106 mining area, which is located in the first section, inside the open-off cut is the magmatic intrusive area, and the outside is near the protection coal pillar of 106 mining area alleys. The length of the face strike is $753.3 \mathrm{~m}$ on average, the length of the slope is $189 \mathrm{~m}$. The level of the working face is $-620 \mathrm{~m}-600 \mathrm{~m}$. The coal seam was mined by fully-mechanized mining method, and the roof management is all caving method.

According to the data of the boreholes 2010-4, 9-5, 02-19 and 1061-1, there are three layers of hard thick magmatic rock above 1061 working face, and two layers of magmatic rock in the local district, which are nearby the open-off cut. The change of the thickness of magmatic rock and the space between the coal seam is relatively big. The range and trend are as follows:

The lower magmatic rock: Range in 27 60 m. The thickness is gradually increasing. The thickest area is located nearby the stop line the thickness can reach $60 \mathrm{~m}$. The thickness changes from large to small. The middle magmatic rock: Range in $27 \sim 46 \mathrm{~m}$. The thickness changes from small to large. The upper magmatic rock: Range in 26 36 m. The thickness changes from large to small along the working face advancing direction. 


\section{Mechanical Analysis of Magmatic Rock's Fracture}

The data of the boreholes show that there are three layers of thick hard magmatic rock above 10 coal seam, there are two layers of magmatic rock in local district, and the change of the thickness of magmatic rock and the space between the coal seam is relatively big. According to the mechanical parameters test of borehole R414, the average tensile strength is $6.25 \mathrm{MPa}$, the displacement angle of strata is $75^{\circ}$. Gain the value of the thickness and space between the three layers of magmatic rock, as shown in Table 1 .

Table 1 Data based on the boreholes

\begin{tabular}{lcccc}
\hline Items & Thickness $(\mathrm{m})$ & $\begin{array}{l}\text { Space between } \\
\text { coal seam }(\mathrm{m})\end{array}$ & $\begin{array}{l}\text { Space between first } \\
\text { layer of magmatic } \\
\text { rock }(\mathrm{m})\end{array}$ & $\begin{array}{l}\text { Space between } \\
\text { second layer of } \\
\text { magmatic rock (m) }\end{array}$ \\
\hline First layer & 31 & 232 & 63 & 56 \\
\hline Second layer & 29 & 326 & 148 & 56 \\
\hline Third layer & 31 & 411 & & \\
\hline
\end{tabular}

Fracture Span of Magmatic Rock. The fracture span of magmatic rock includes two parts along the dip and strike of working face, the first step is to calculate the limit collapse distance of magmatic rock, and the second is first fracture span and periodic fracture span of magmatic rock ${ }^{[1-4]}$.

Magmatic rock will gradually bend and subside with the working face mined, resulting in pressure abnormally appearing in working face. When the large area of hanging magmatic rock reaches its limit collapse distance, the fracture occurs, which will cause rock burst that threatens the safety of coal mine production. The overlying rock of the 106 mining area includes three layers of magmatic rock. After the mining of the coal seam, the lower part of magmatic rock subsides, it can be regarded as an ends-fixed beam. When the large area of hanging magmatic rock attains its limit collapse distance, it will fracture, and the limit collapse distance $L_{m}$ can be determined by Eq. 1:

$$
L_{m}=l_{m}+2 \sum H \cot \beta \square l_{m}=H \sqrt{\frac{2 R_{T}}{q}}
$$

where $L_{m}$ is the limit collapse distance of the working face, $l_{m}$ is the limit collapse distance of magmatic rock, $H$ is the thickness of magmatic rock, $\sum H$ is the distance between coal seam and magmatic rock, $R_{T}$ is the uniaxial tensile strength of magmatic rock, $\beta$ is the displacement angle of strata, $q$ is the unit load loaded on the magmatic rock.

According to the comprehensive histogram of 106 mining area, the average thickness of the first layer of magmatic rock is $46 \mathrm{~m}, 181 \mathrm{~m}$ away from 10 coal.The average thickness of the second layer of magmatic rock is $38 \mathrm{~m}, 295 \mathrm{~m}$ away from 10 coal. The average distance between the two magmatic rock is $68 \mathrm{~m}$.The length of the open-off cut of 1061 working face and roadways on both sides is $189 \mathrm{~m}$, the length of working face strike is about $753.3 \mathrm{~m}$. So the ratio between the thickness of the first layer of magmatic rock and the length of working face is about 1:16, and the second layer is about 1:20, so the magmatic rock can be viewed as a thin plate. According to the thin plate theory, it can calculate that how long the working face advances will the magmatic rock roof fracture ${ }^{[5-8]}$.

Owing to the high intensity of magmatic rock, and the working face length is longer, so the thin plate theory can calculate and analyze magmatic rock movement. According to the theory of thin plate, the fracture span calculation equation is:

$$
\left\{\begin{array}{l}
a=\frac{\beta}{\sqrt{3-2 \beta / b}} \\
\beta=\sqrt{\frac{4 \sigma_{t} k m^{2}}{1.3 \gamma \sum H \cos \alpha}}
\end{array}\right.
$$


where $a$ is the fracture span of magmatic rock, $b$ is the span of the magmatic rock along the working face dip direction, $\sigma_{\mathrm{t}}$ is the rock tensile strength, $k$ is the coefficient of rock crack, and $\mathrm{k}=0.75, m$ is the thickness of bracket layer of the strata, $\gamma$ is the unit weight of rock which is $2.5 \times 10^{4} \mathrm{~N} / \mathrm{m}^{3}, \alpha$ is the dip angle which is $8^{\circ}$.

The displacement angle of strata between 10 coal and the magmatic rock is $75^{\circ}, a$ and $b$ are shown in Fig. 1. And in Fig. 1 (a), $L_{Q X}=b+2 \sum H \cot \beta, L_{Q X}$ is the width of 1061 working face.

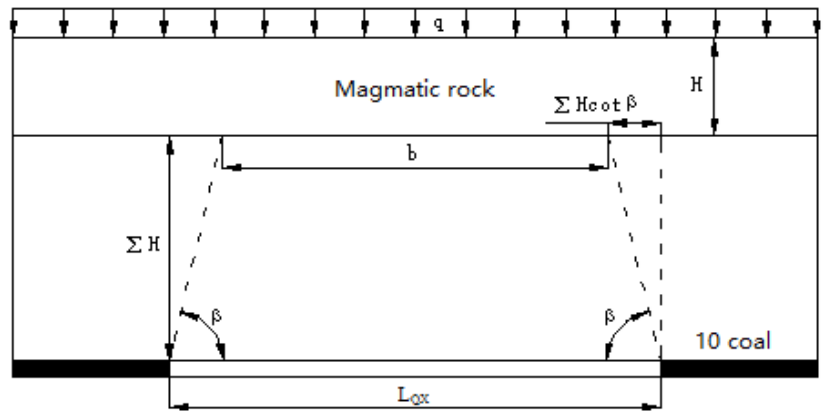

(a) Face dip direction

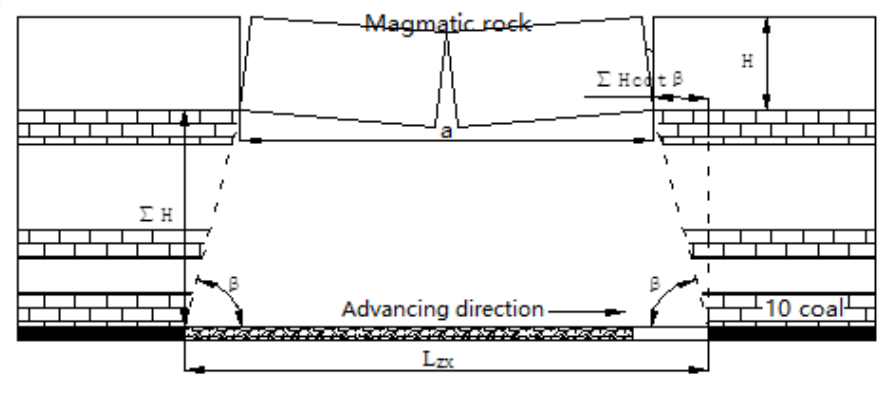

(b) Face strike direction

Fig. 1 Mechanic model

When the uniaxial tensile strength of magmatic rock, the thickness of the magmatic rock, the total thickness of the strata and the span of the magmatic rock along the working face dip direction are known, the fracture span of magmatic rock can be calculated by Eq. 2 .

After the mining of 1061 working face, the lower part of magmatic rock subsides, the advancing distance of the working face can be calculated by: $L_{Z X}=a+2 \sum H \cot \beta$

Analysis of the Fracture of Magmatic Rock. According to the data in Table 1 and Eq. 1, the result is : $L=H \sqrt{\frac{2 R_{T}}{q}}+2 \sum H \cot \beta=186 \mathrm{~m}$

The total length of the open-off cut and the roadways on both sides is $189 \mathrm{~m}$, therefore, according to the calculation result, when the working face advance to certain distance, the magmatic rock will cave.

Then calculate the advancing length of the working face. Through Eq. 2 and Eq. 3, when the magmatic rock fractures, the advancing length of the working face is: $L_{Z X}=a+2 \sum H \cot \beta=226 \mathrm{~m}$.

So the first layer of magmatic rock is expected to fracture when the face advances about $226 \mathrm{~m}$.

According to the data in Table 1 and Eq. 1, the result is:

$$
L=H \sqrt{\frac{2 R_{T}}{q}}+2 \sum H \cot \beta=236 \mathrm{~m}, L=H \sqrt{\frac{2 R_{T}}{q}}+2 \sum H \cot \beta=261 \mathrm{~m}
$$

The total length of the open-off cut and the roadways on both sides is $189 \mathrm{~m}$, so in the process of mining, the second and third layer of magmatic rock fracture will not occur.

Magmatic Periodic Fracture Span Estimation. Magmatic periodic fracture span can be determined by the following equation, use the average of the calculation of the adjacent periodic fracture span $C_{i}$ and $C_{i+1}$ as the periodic fracture span ${ }^{[9-12]}$.

$$
C_{i+1}=\sqrt{0.25 c_{i}^{2}+\frac{0.33 m_{c} \cdot \sigma_{t} \cdot k}{\gamma \cdot \cos \alpha}}-0.5 c_{i}
$$

According to the calculation, the first layer of magmatic rock will fracture in the process of mining, according to the fracture distance and the correlation coefficient, magmatic rock periodic fracture span is calculated as shown in Table 2. The advancing distance of the working face can be calculated by Eq. 4 . The results are shown in Table 3.

$$
L_{i}=C_{i}+2 \sum H \cot \beta
$$


Table 2 The periodic fracture span of the first layer of magmatic rock

\begin{tabular}{|c|c|c|c|c|c|c|}
\hline & $\begin{array}{l}\text { First } \\
\text { fracture span } \\
\mathrm{C}_{0}(\mathrm{~m})\end{array}$ & $\begin{array}{l}\text { First } \\
\text { periodic } \\
\text { fracture } \\
{\text { span } C_{1}(\mathrm{~m})}\end{array}$ & $\begin{array}{l}\text { Second } \\
\text { periodic } \\
\text { fracture span } \\
\mathrm{C}_{2}(\mathrm{~m})\end{array}$ & $\begin{array}{l}\text { Third } \\
\text { periodic } \\
\text { fracture } \\
\text { span } C_{3}(\mathrm{~m})\end{array}$ & $\begin{array}{l}\text { Forth } \\
\text { periodic } \\
\text { fracture } \\
{\text { span } C_{4}(\mathrm{~m})}\end{array}$ & $\begin{array}{l}\text { Fifth } \\
\text { periodic } \\
\text { fracture } \\
\text { span } C_{5}(\mathrm{~m})\end{array}$ \\
\hline Fracture span & 101 & 21.1 & 41.3 & 34.2 & 36.5 & 35.7 \\
\hline
\end{tabular}

Table 3 Working face advancing distance when the first layer of magmatic rock periodically fractures

\begin{tabular}{lcccccc}
\hline & First & Second & Third & Forth & Fifth & Average \\
\hline Advancing distance & 83.5 & 103.6 & 96.5 & 98.8 & 98.1 & 96.1 \\
\hline \multicolumn{7}{l}{ Therefore, the working face advancing distance when the first layer of magmatic rock periodically }
\end{tabular}
fractures is about $96.1 \mathrm{~m}$.

\section{Numerical Simulation}

We use numerical simulation software UDEC2D to analyze the situation of coal seam mining under thick hard magmatic rock. The model size is $700 \mathrm{~m}$ long and $350 \mathrm{~m}$ high. Model boundary conditions of the specific definition is as follow:

The left and right boundaries are horizontal displacement constrained boundaries, namely the velocity and displacement vector in the $\mathrm{x}$ direction are 0 . The upper boundary is free boundary. The lower boundary of the model is all-constrained boundary, namely the velocity and displacement vector in the $\mathrm{x}$ direction and y direction are both 0 .

Set up the numerical model based on the actual embedded depth of coal seam and rock strata distribution. To avoid the influence of boundary effect on the model, reserve $75 \mathrm{~m}$ coal pillars on both sides of the model, namely the working face advances $550 \mathrm{~m}$. The model adopts Mohr-Coulomb criterion to calculate. The rock mechanical parameters are shown in Table 4.

Table 4 Rock mechanical parameters of numerical model

\begin{tabular}{cccccc}
\hline Lithology & $\begin{array}{c}\text { Density } \rho \\
\left(\mathrm{kg} / \mathrm{m}^{3}\right)\end{array}$ & $\begin{array}{c}\text { Bulk modulus K } \\
(\mathrm{GPa})\end{array}$ & $\begin{array}{c}\text { Shear modulus G } \\
(\mathrm{GPa})\end{array}$ & $\begin{array}{c}\text { Cohesion c } \\
(\mathrm{MPa})\end{array}$ & $\begin{array}{c}\text { Friction } \\
\varphi\left({ }^{\circ}\right)\end{array}$ \\
\hline Sandstone & 2600 & 13.095 & 9.016 & 5.4 & 35 \\
\hline Coal seam & 1300 & 5.000 & 2.308 & 1.0 & 28 \\
\hline Mudstone & 2640 & 8.000 & 4.800 & 2.3 & 35 \\
\hline Fine sandstone & 2340 & 12.346 & 8.130 & 5.2 & 37 \\
\hline Magmatic rock & 3000 & 43.500 & 85.000 & 46.0 & 45 \\
\hline Siltstone & 2570 & 14.881 & 10.246 & 5.0 & 35 \\
\hline
\end{tabular}

When carrying out the numerical simulation, we use the data in Table 1, and the results are as follows. 


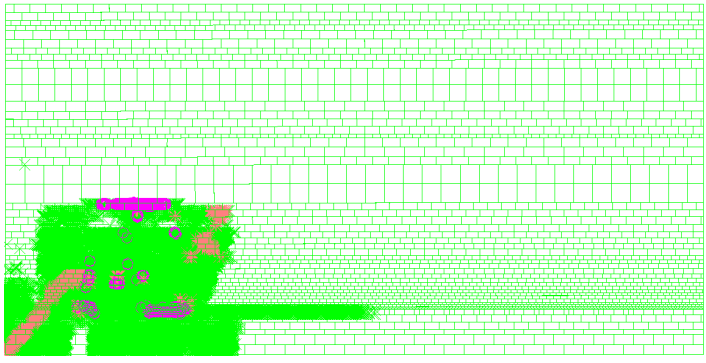

(a ) Face advanced $100 \mathrm{~m}$

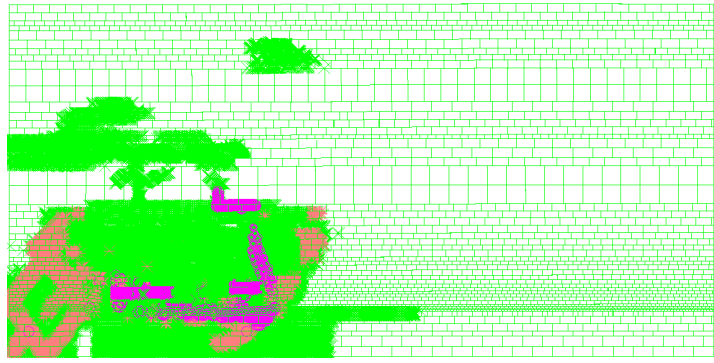

(c) Face advanced $190 \mathrm{~m}$

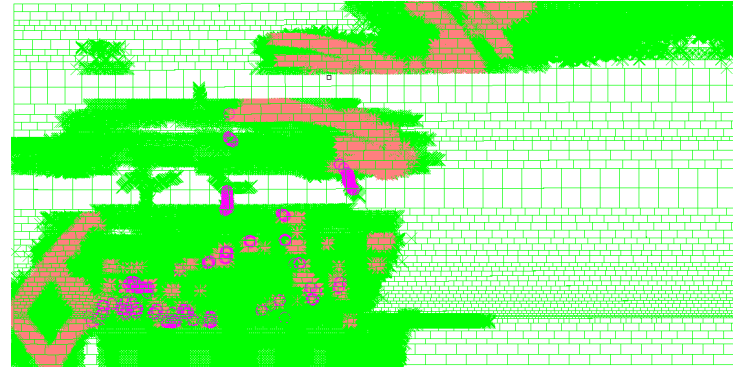

(e ) Face advanced $250 \mathrm{~m}$

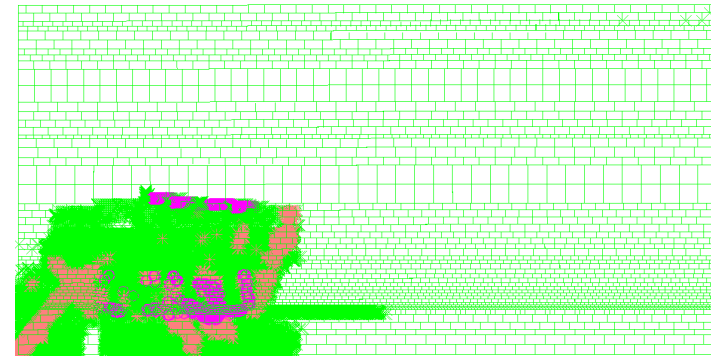

(b ) Face advanced $160 \mathrm{~m}$

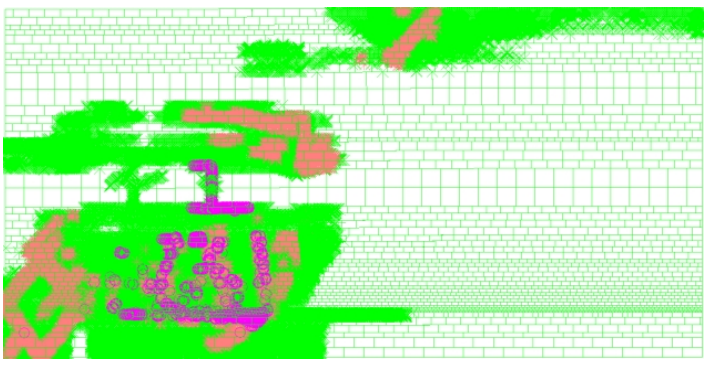

(d ) Face advanced $220 \mathrm{~m}$

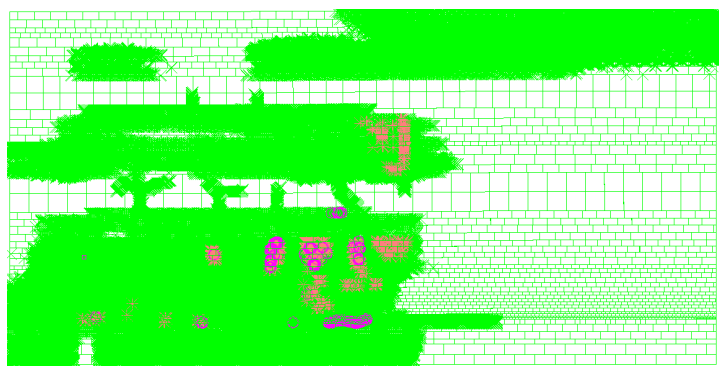

(f) Face advanced $280 \mathrm{~m}$

Fig. 2 Changes of plastic zones of magmatic rock in the process of mining

The plastic zone distribution in the process of rock stability after the mining of 1061 working face is shown in Fig. 2. Through the figure, we can see that a large tensile failure area is formed above mined-out area, of the and shear and bulk failure zones are formed on both sides. The plastic zone recovers to the elastic state with the gradual stability of the rock strata. And the plastic zone of the overlying magmatic rock develops rapidly due to the expansion of the range of abscission layer and dislocation.

When the face advances $190 \mathrm{~m}$, larger tensile failure occurs inside the magmatic rock, and the range has been close to half the thickness of the magmatic rock, but due to the large thickness and great strength of magmatic rocks, the magmatic rock basically remains stable. When the face advances $220 \mathrm{~m}$, apparent tensile failure occurs inside and at the bottom of the magmatic rock, and relatively long strip tensile failure appears throughout the magmatic rock where the range of abscission layer is big, namely the magmatic rock has fractured by the moment. The plastic zones in magmatic rock increase with the working face advancing, which shows that magmatic rock occur gradually fractures, which is very close to the theoretical calculation result $226 \mathrm{~m}$. Synthesizing theoretical analysis and numerical simulation, the fracture length of the magmatic rock is about $220 \mathrm{~m}$.

\section{Conclusions}

Based on the geological conditions of the working face, we can obtain following conclusions:

(1) After the mining of 1061 working face, the mining width will reach $189 \mathrm{~m}$, then the first layer of 
magmatic rock may fracture. The limit collapse distance of the first layer of magmatic rock is about 186 $\mathrm{m}$, with the advancing distance of $226 \mathrm{~m}$. At this moment, the workers should strengthen the monitoring and take timely measures to prevent the rock burst disaster. The working face advancing distance when the first layer of magmatic rock periodically fractures is about $96.1 \mathrm{~m}$.

(2) After the mining of 1061 working face, the width of the mined-out area is less than the limit collapse distance of the second and third layer of magmatic rock, so they will not fracture during the period of mining, but may fracture during the period of mining the latter working face.

(3) Based on theoretical analysis and numerical simulation, the fracture distance of the magmatic rock is about $220 \mathrm{~m}$.

\section{References}

[1] Qi Qingxin, Li Hongyan, Pan Junfeng, et al. Stress control theory and practice of rock burst prevention[J]. Coal Mining Technology, 2011, 03:114-118.

[2] Jiang Yaodong, Pan Yishan, Jiang Fuxing, et al. State of the art review on mechanism and prevention of coal bumps in China[J]. Journal of China Coal Society, 2014, 39(02):205-213.

[3] Wang Zuotang, Xin Lin, Fu Zhenkun, et al. Caculation and Prediction on main roof failure and falling periodical distance of hard magmatic rock[J]. Coal Engineering, 2010, 07:58-60.

[4] Gao Mingshi,Dou Linming, Zhang Nong et al. The strength of the roadway surrounding rock control rock burst strong mechanics analysis model and its application[J]. Rock and soil mechanics, 2008, 29(02):359-364.

[5] Zhai Suoye, Zhang Kaizhi. "Analysis on key layer of overlying strata with elastic slab theory". Chinese Journal of Rock Mechanics and Engineering, 2004, 23(11):1856-1860.

[6] Peng Yongwei, Qi Qingxin, MAO Debing, et al. In the process of mining coal seam impact risk assessment method research[J]. Journal of coal mining, 2010, (01):1-3+7.

[7] Guo Xiaoqiang, Lu Caiping, Hu Jiang, et al. The main key strata of overburden rock fracture law study[J]. Journal of mining safety and environmental protection, 2011, 18(01):23-26+6.

[8] Pan Yue, Wang Zhiqiang, Li Aiwu. During the initial fracture ahead of working face hard roof deflection, bending moment and the analytical solution of the energy change[J]. Journal of rock mechanics and engineering, 2012, 21(09):32-41.

[9] Li Zhenlei, Dou Linming, Cai Wu, et al. Deep thick coal seam coal pillar type fault mechanism of rock burst study[J]. Journal of rock mechanics and engineering, 2013, 32(02):333-342.

[10] Pan Junfeng, MAO Debing, Lan Hang, et al. The current situation of prevention and control of rock bursts in coal mines and prospects[J]. Journal of coal science and technology, 2013, 41(06): $21-25+41$.

[11] Li Zhenlei, Dou Linming, Cai Wu, et al. Investigation and analysis of the rock burst mechanism induced within fault-pillars[J]. International Journal of rock mechanics and engineering, 2014, 70: 192-200.

[12] Qi Qingxin, Li Xiaolu, Zhao Shankun. Coal mine bumps stress control theory and the practice[J]. Journal of coal science and technology, 2013, 32(06):1-5. 